Article

\title{
Second Law Analysis of a Mobile Air Conditioning System with Internal Heat Exchanger Using Low GWP Refrigerants
}

\author{
Vicente Pérez-García ${ }^{1, *}$, Juan M. Belman-Flores ${ }^{1}$, José L. Rodríguez-Muñoz ${ }^{2}$, \\ Víctor. H. Rangel-Hernández ${ }^{1}$ and Armando Gallegos-Muñoz ${ }^{1}$ \\ 1 Department of Mechanical Engineering, Engineering Division, Campus Irapuato-Salamanca, \\ University of Guanajuato, Salamanca 36885, Mexico; jfbelman@ugto.mx (J.M.B.-F.); \\ vrangel@ugto.mx (V.H.R.-H.); gallegos@ugto.mx (A.G.-M.) \\ 2 Department of Metal-Mechanical, Technological University of Guanajuato Southwest, \\ Valle-Huanimaro Km. 1.2, Valle de Santiago 38400, Mexico; ingrom79@gmail.com \\ * Correspondence: v.perez@ugto.mx; Tel.: +52-464-647-9940
}

Academic Editors: Pouria Ahmadi and Behnaz Rezaie

Received: 10 March 2017; Accepted: 17 April 2017; Published: 19 April 2017

\begin{abstract}
This paper investigates the results of a Second Law analysis applied to a mobile air conditioning system (MACs) integrated with an internal heat exchanger (IHX) by considering R152a, R1234yf and R1234ze as low global warming potential (GWP) refrigerants and establishing R134a as baseline. System simulation is performed considering the maximum value of entropy generated in the IHX. The maximum entropy production occurs at an effectiveness of $66 \%$ for both R152a and R134a, whereas for the cases of R1234yf and R1234ze occurs at 55\%. Sub-cooling and superheating effects are evaluated for each one of the cases. It is also found that the sub-cooling effect shows the greatest impact on the cycle efficiency. The results also show the influence of isentropic efficiency on relative exergy destruction, resulting that the most affected components are the compressor and the condenser for all of the refrigerants studied herein. It is also found that the most efficient operation of the system resulted to be when using the R1234ze refrigerant.
\end{abstract}

Keywords: mobile air conditioning; exergy; efficiency; maximum entropy production; IHX

\section{Introduction}

During the last two decades, R134a has been one of the most important refrigerants used in domestic refrigeration, air conditioning systems, and chillers. However, according to the restrictions on chlorofluorocarbons and hydrofluorocarbons agreed in the Montreal Protocol [1], R134a has a global warming potential (GWP) of approximately 1300, thus contributing significantly to the greenhouse effect. To protect the environment, different regulations that limit the use of refrigerants with high GWP values have been approved [2], so the refrigeration industry is developing new working fluids that have the least possible impact on the environment [3,4].

R1234yf, R1234ze, and R152a are alternatives to R134a with low GWP values (less than 150) and also have zero ozone depletion potential. Thus, some papers in the literature are related to vapor compression cycles studies evaluating these refrigerants [5-7].

The drop-in replacement analysis of R134a has been studied by some researchers around the world. For example, Lee and Jung [8] evaluated the energetic performance in an experimental test bench working with R1234yf under winter and summer conditions. They concluded that it is a suitable refrigerant in mobile air conditioning systems, replacing R134a. According to studies using R1234yf, Zhao et al. [9] evaluated a mobile air conditioning system (MACs) under different load conditions and 
found that the optimum refrigerant charge of R1234yf was approximately $90 \%$ compared with that of R134a under the same MAC system. Zhao [10] studied a MACs working with R1234yf under many operating conditions and concluded that increasing sub-cooling temperature from $1 \mathrm{~K}$ to $10 \mathrm{~K}$ could improve the Coefficient of performance (COP) of the system and its cooling capacity by $15 \%$.

Other researchers like Zilio et al., [11], experimentally evaluated R134a and R1234yf in a compact MACs in a variable speed compressor, particularly some modifications to the cycle were made showing that the R1234yf is an attractive proposition from an energy point of view. In this context, there have been many investigations involving changes to the vapor compression cycle in order to find improvements in the energy performance of the cycle when working with R1234yf. Jignesh and Rangesh [7] proposed the use of an IHX, considering an effectiveness of 50\%. They concluded that the R1234yf operating cycle decreases by between 3\% and 5\% with respect to the Coefficient of Performance (COP) obtained with R134a without an internal heat exchanger.

In addition, Navarro-Esbrí et al. [12] experimentally evaluated a refrigeration system using R1234yf, and with an IHX, they compared the system using R134a, the results of their study showed that the COP with R1234yf and IHX was only 8\% lower compared to the COP of R134a. Gomaa [13] conducted an experimental study comparing three refrigerants proposed as substitutes for R134a; they concluded that R1234yf has the best thermal performance but compared with R1234ze and R152a refrigerants, it has the lowest energy performance.

According to exergy studies, Yataganbaba et al. [14] developed an exergy analysis making comparisons between R134a, R1234yf, and R1234ze in a single cycle. They found that the COP of R134a was higher than the R1234yf, however, this difference was slight and, therefore, R1234yf was a good choice as a replacement for R134a. Özgür et al. [15], conducted an exergy analysis between R1234yf and R134a, concluding that both refrigerants showed a similar behavior under the same operating conditions. It is also mentioned that R1234yf has lower irreversibility than R134a, so this refrigerant was recommended as a good alternative for replacement in refrigeration systems.

Cho and Park [16] conducted an exergy analysis of a MAC including an IHX and evaluating the system at different compressor speeds, both refrigerants R1234yf and R134a were compared, and very similar behaviors were found. Pottker and Hrnjak [17] studied the effect of sub-cooling on the COP of a MAC system using both R134a and R1234yf as refrigerants; experimental results showed good performance for the system operating with R1234yf when an IHX was used with a relatively high degree of sub-cooling.

Soudabeh et al. [18] made a Second Law comparison between R1234yf and R134a in a single cycle for MACs, concluding that the major exergy destruction and entropy generation occurs in the compressor when an isentropic efficiency of around $60 \%$ is taken into account, which was obtained from experimental measurements reported by the authors.

Kadir et al. [19] made a theoretical comparative analysis of R152a as alternative refrigerant toR134a. The authors's results show that R152a can be considered a good drop-in replacement for R134a in the air conditioning systems of modern automobiles since it has the same pressure ratio as R134a. Thus, there is no need for any considerable modifications to the system. Also, it was found that R152a and R134a do not lead to any significant differences on the performance of the refrigeration system.

Based on the literature reviewed, it can be seen that the vapor compression system with R1234yf has an energy performance very similar to the one that uses R134a. However, it was also observed that there are few papers where a comparison is made based on the First and the Second Laws of Thermodynamics including exergy analysis. Such studies provided a better understanding of the irreversibility and exergy destruction of the main components of a vapor compression system. The contribution of this study is to show more evidence of the exergy destruction, exergetic effectiveness, and Second Law of efficiency of the system. Comparison of the above mentioned parameters between R134a and the three alternative refrigerants used in automotive air conditioning such as R152a, R1234yf, and R1234ze when an IHX is introduced, considering the effectiveness of this as a principal variable. Moreover, in this paper, we present the influence of IHX effectiveness with 
respect the Second Law efficiency and entropy and exergy analysis of the system when the condition of maximum entropy for this element is applied.

\section{Theoretical Analysis}

\subsection{Scheme Description}

The most commonly used air conditioning systems in automobiles are: (a) the Receiver Drier Thermostatic Valve (RD-TX) and (b) the Accumulator Drier Orifice Tube (AD-OT) [20]. Of these two systems, only the first one can control the degree of superheating through the expansion valve. Because of this, the Receiver Drier Thermostatic Valve (RD-TX) system is analyzed in this paper. Further, we contemplate the integration of an IHX into the system in order to contribute to an increase in the efficiency of the cycle.

Figure 1a shows the scheme of the RD-TX + IHX system, illustrating the main components. Figure $1 \mathrm{~b}$ shows a T-s diagram of this system, where the refrigerant enters the compressor as superheated steam (1), increasing its energy in the compressor and exits at an elevated temperature and pressure (2), then enters the condenser to release energy and reduce its temperature (3). If sub-cooling is considered, the refrigerant reduces its temperature (4). Afterwards, when the IHX is used, the refrigerant enters the counter-flow heat exchanger to obtain a sub-cooling effect that will produce an increase in the refrigeration capacity. Subsequently, the refrigerant exits subcooled (5) and enters the expansion valve where it reduces its pressure and goes to the evaporator (6), here a process of heat absorption by the refrigerant occurs and at the evaporator exit (7), it is possible have a control of superheating degree (8) using the expansion valve. Once the refrigerant leaves the evaporator, IHX enters and an additional superheating is produced (1), which enters the compressor and the cycle is repeated.

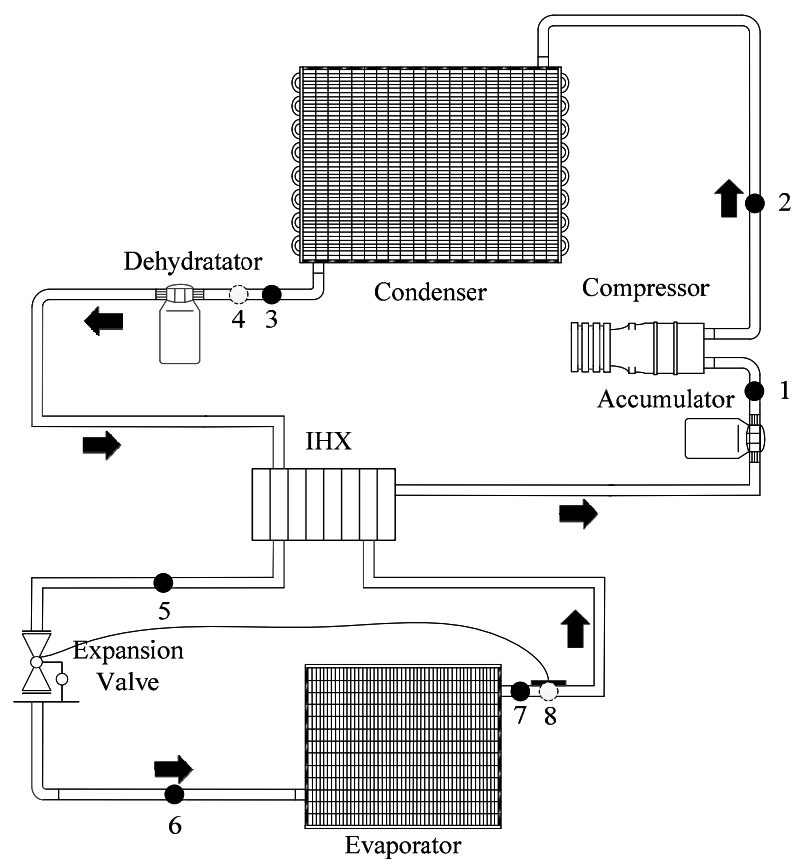

(a)

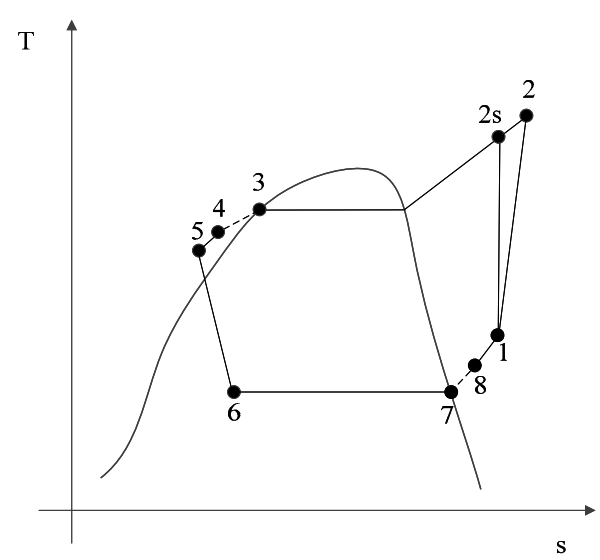

(b)

Figure 1. (a) Receiver Drier Thermostatic Valve + IHX Cycle, (b) T-s diagram.

According to Figure 1, the combination of the accumulator and the IHX provides the following advantages: 
1. To allow certain excess amounts of liquid supply to the evaporator in order to simplify the control system and enhance heat transfer;

2. To withdraw or to deliver extra charge of refrigerant for the regulation of the high side pressure by means of the throttling valve;

3. To hold a sufficient amount of liquid to cover the needs under all possible working conditions and to compensate unavoidable losses by leakage over a reasonable time;

4. To introduce suitable amount of lubricant into the compressor by means of either a capillary tube or throttling valve to the suction line;

5. To provide sufficient gas volume to avoid excessive build-up pressure when the plant is idle at extremely high room temperature.

\subsection{Operational Scheme Conditions}

According to the AC benchmark system of [21], hot and humid air flows through the evaporator to diminish its temperature, thereby reducing its corresponding dew temperature to remove its moisture. The operating conditions of the simulations carried out in this work are shown in Table 1. For the sake of simplicity, an average value $(287.95 \mathrm{~K})$ of the dew point temperature is considered by considering the maximum $(290.75 \mathrm{~K})$ and the minimum $(285.15 \mathrm{~K})$ value, holding the same relative humidity $(60 \%)$. The evaporation temperature is set up at $5 \mathrm{~K}$ lower than the dew point inside the air conditioner and the condensation temperature $20 \mathrm{~K}$ higher than the temperature outside. The values are presented in Table 1, and the temperature conditions of evaporation and condensation were established by [21] with the aim of saving energy in the compressor.

Table 1. Operational conditions according to [21].

\begin{tabular}{cc}
\hline Item & Value \\
\hline Evaporation temperature, $T_{e v}$ & 282.95 \\
Condensation temperature, $T_{c o n}$ & 327.15 \\
Indoor temperature, $T_{L}$ & 296.15 \\
Outdoor temperature, $T_{H}$ & 307.15 \\
Isentropic efficiency, $\eta$ & $75 \%$ \\
\hline
\end{tabular}

\subsection{Energy and Exergy Analysis}

Energy direction flow cannot be determined by the First Law of Thermodynamics (Equation (1)) because this is a statement of the law of conservation of energy that readily yields the energy balance of the system:

$$
q_{e v}+W_{c}=q_{c o n}
$$

The energy analysis allows to determine the $C O P$, which is a measure of the energy performance of the system. This parameter is written as:

$$
\mathrm{COP}=\frac{q_{e v}}{W_{c}}
$$

According to the Second Law of Thermodynamics, it is possible to determine the energy flow direction and the Second Law Efficiency can be defined as Equation (3) indicates:

$$
\chi=\frac{C O P}{C_{R}}
$$

where $C O P_{R}$ is defined by Equation (4):

$$
\operatorname{COP}_{R}=\frac{T_{L}}{T_{H}-T_{L}}
$$


The main purpose for exergy analysis is to determine where and how losses occur so that energy may be used most efficiently. The exergy analysis is applied to the components shown in Figure 1. Simulations are carried out according to the following assumptions:

- $\quad$ Isentropic efficiency of the compressor;

- Isenthalpic expansion;

- $\quad$ Pressure drops in all the connecting pipes and heat transfer between the connecting pipes and the environment are negligible.

Exergy content of a pure substance is defined according to Equation (5):

$$
e=\left(h-h_{0}\right)-T_{0}\left(s-s_{0}\right)
$$

For each component, exergy loss can be calculated by Equation (6):

$$
\Delta e=e_{\mathrm{sup}}-e_{\text {rec }}
$$

and its exergetic efficiency by:

$$
\sigma=\frac{e_{\text {rec }}}{e_{\text {sup }}} \times 100
$$

Exergy analysis can help to locate system non-idealities by ranking the components of the system based on the significance of their parts in destroying exergy in the system. In this sense, relative exergy destruction in each element of system can be calculated by Equation (8):

$$
\Psi=\frac{\delta_{e q}}{\delta_{\text {sys }}} \times 100
$$

where $\delta_{\text {sys }}$ can be obtained by:

$$
\delta_{s y s}=\delta_{c}+\delta_{c o n}+\delta_{e v}+\delta_{e x}+\delta_{I H X}
$$

Condenser rejects heat to the cooling air by an amount $q_{c o n}$ at the variable sink temperature. For the heat transfer occurring at a variable temperature, the entropic average temperature for the source and sink as detailed by [22] or the effective reservoir temperature detailed by [23]. The entropic average temperature is often used to streamline and simplify the analysis of processes involving variable temperature heat transfer [24]. According to this, the effective reservoir temperature $T_{c o n}$ is defined as the reference temperature at which the exergy of a reservoir fluid entering at heat exchanger (condenser in this case) is equal to its exergy leaving the heat exchanger. Thus:

$$
h_{2}-h_{3}=T_{\text {con }}\left(s_{2}-s_{3}\right)
$$

or:

$$
T_{\text {con }}=\frac{h_{2}-h_{3}}{s_{2}-s_{3}}
$$

Considering that heat from the condenser is rejected to the cooling air at a constant temperature, and according to Figure 1a, exergy balance for each component is listed in Table 2.

Dincer and Rosen [25] argued that properties of the reference environment, determine the exergy of a system or stream. Thus, it is of utmost importance that we define the condition of reference to simplify the mathematical model. For the present calculation, we take a temperature of $298.15 \mathrm{~K}$ and a pressure of $101.3 \mathrm{kPa}$.

Finally, Table 2 presents each of the main system components (compressor, condenser, expansion valve, IHX, and evaporator) with the respective modeling equations for calculating the thermodynamic variables in the cycle. 
Table 2. Components modeling.

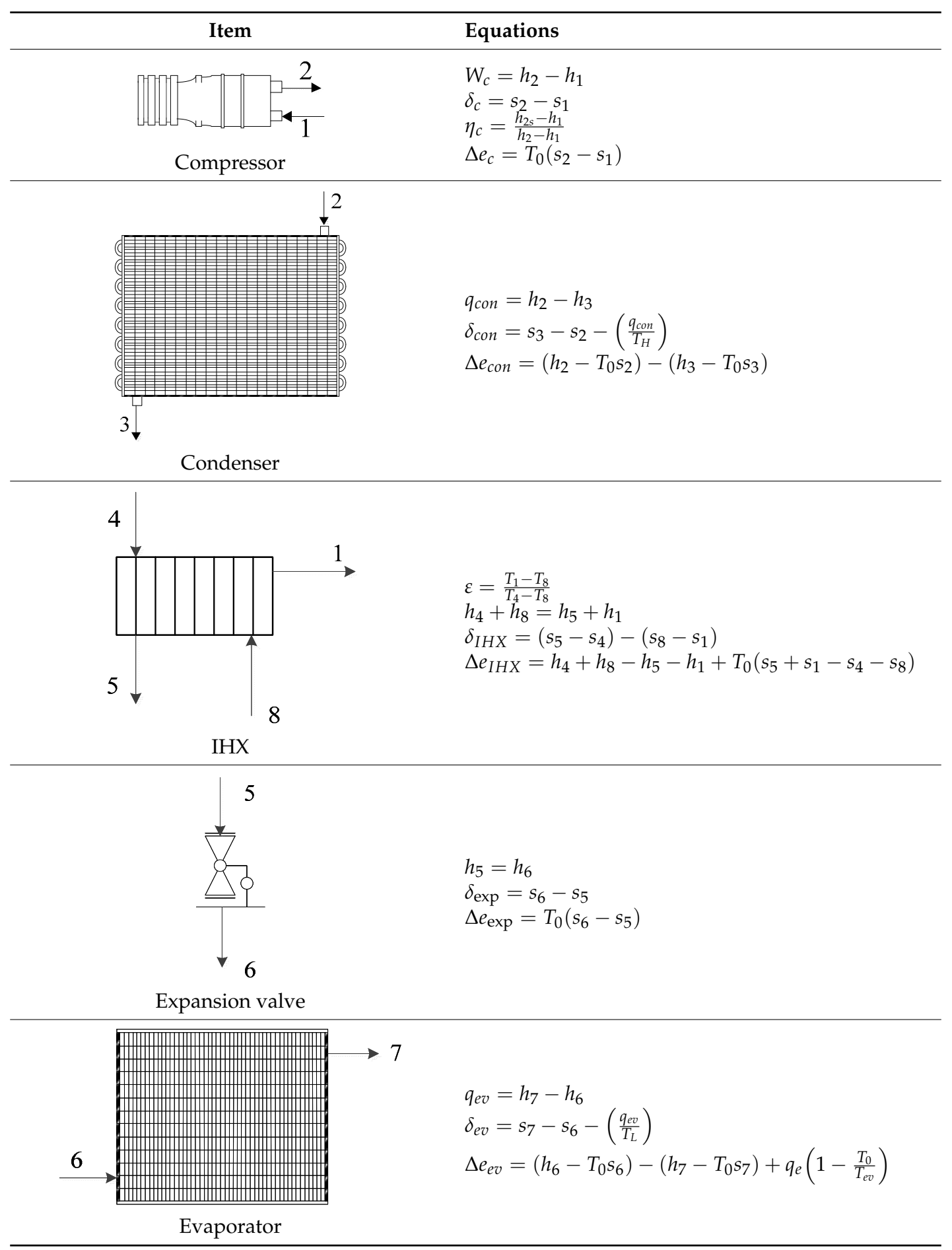

\section{Results}

According to the operating conditions of Table 1 and the characterization presented in Table 2, the main results obtained by the simulation configuration analyzed for the proposed refrigerants are presented in this section. All simulations were made using the Engineering Equation Solver (EES) software.

Figure 2 shows the effect of the IHX on the second law efficiency of the system for the different refrigerants used in this study. The baseline is the refrigerant R134a. The results are obtained by 
considering a condensation temperature, $T_{c o n}$, of $\mathrm{TH}+20 \mathrm{~K}$ and considering a superheating and sub-cooling temperature equal to zero. It can be observed that second law efficiency of R1234ze exceeds to R134a from effectiveness up to 10\%, while R1234yf second law efficiency is maintained below the R134a efficiency over the entire operating range of IHX. In terms of R152a, the integration of the IHX does not have a considerable effect on the efficiency of the cycle.

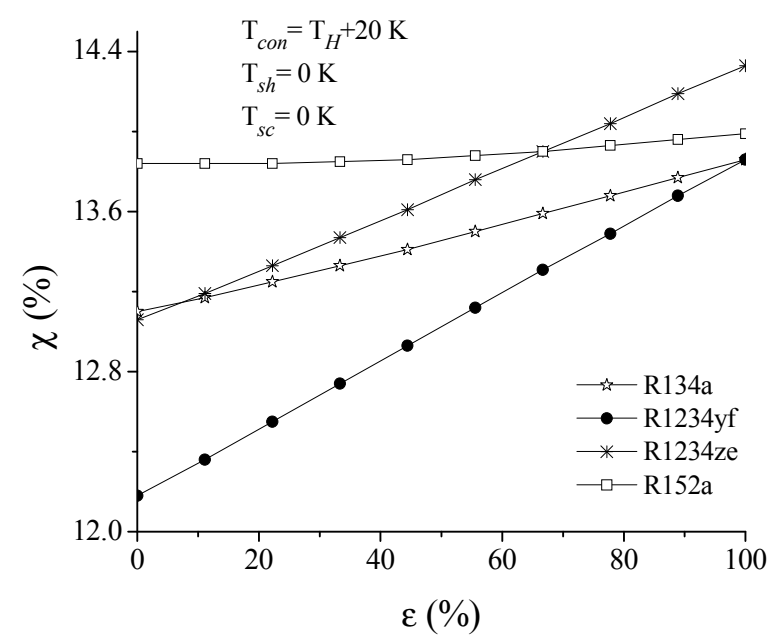

Figure 2. Second Law efficiency cycle vs. IHX Effectiveness.

Finally, through these results, it is possible to support the importance of integrating an IHX component in the whole system. It is noteworthy that the R1234ze refrigerant is the most optimum for this confinguration.

As for the IHX performance, Figure 3 shows the effect of the effectiveness on the entropy generation for the different refrigerants. It can be seen that the refrigerant with the highest entropy generation values is found to be the R152a, this is because its specific heat capacity is higher than that of the R1234yf, R134a, and R1234ze. The maximum entropy production occurs at an effectiveness of $66 \%$ for R152a and R134a, whereas for the R1234yf and R1234ze refrigerants it is shown at 55\%, approximately. In Sections 3.1 and 3.2, Figures 4-7, respectively, have been obtained by taking into account this value in order to know the effect on the system when the entropy generated in the IHX is maximum.

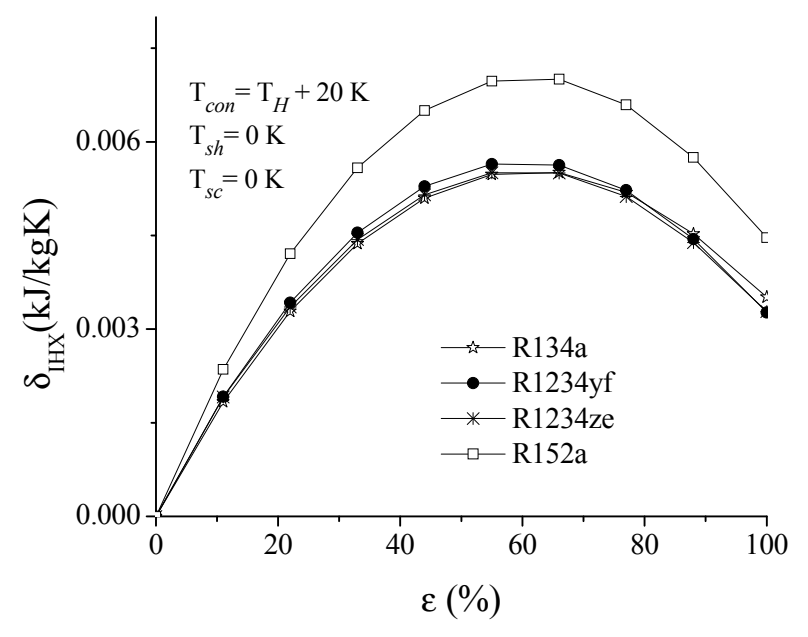

Figure 3. Entropy production in IHX as a function of effectiveness. 


\subsection{Superheating and Sub-Cooling Influence}

Figure 4 shows the superheating degree effect on the second law efficiency of the cycle. In particular, Figure 4a depicts the effect of the superheating degree on the second law efficiency of the system when the sub-cooling degree is assumed to be zero. It can be appreciated that the pattern of second law efficiency for the different refrigerants is quite similar as the superheating degree is increasing; however, the effect of this last parameter when the system uses R1234yf is higher than the other refrigerants, showing an increase in second law efficiency of up to $19 \%$ in comparison with the R134a refrigerant.

It is also observed that when the superheating degree is less than $5 \mathrm{~K}$, the second law efficiency for R152a is 7\% higher than the R1234yf. It is also found that the second best refrigerant, in terms of the second law efficiency, is the R1234ze when the superheating degree effect is increased. Figure $4 \mathrm{~b}$ shows the effect of the superheating degree when a sub-cooling degree of $5 \mathrm{~K}$ is considered. According to it, the second law efficiency of the system is practically the same when the superheating degree moves in a range of 6 to $8 \mathrm{~K}$ for the refrigerants R1234yf and R1234ze. In general, the superheating degree does not have a significant effect on the second law efficiency of the cycle.

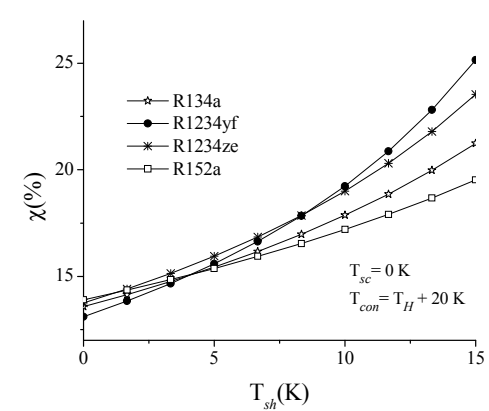

(a)

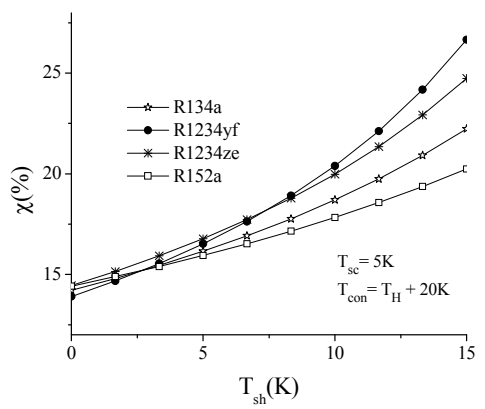

(b)

Figure 4. Effect of superheating degree on the second law efficiency when the entropy production in the IHX is maximum: (a) sub-cooling equal to zero; (b) sub-cooling equal to $5 \mathrm{~K}$.

Figure 5a illustrates the effect of superheating degree on the second law efficiency for the different refrigerants. In this particular case, the R1234ze shows the highest second law efficiency value among the different refrigerants at a sub-cooling temperature of $4.5 \mathrm{~K}$, while the R1234yf shows the lowest one. The difference in the second law efficiency between the two refrigerants is only $3.5 \%$ for a sub-cooling degree of $15 \mathrm{~K}$.

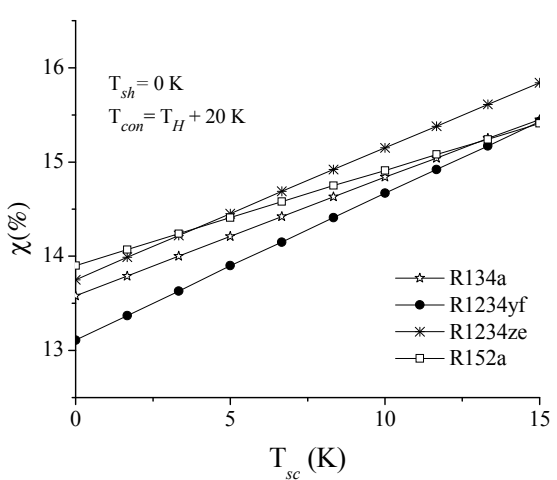

(a)

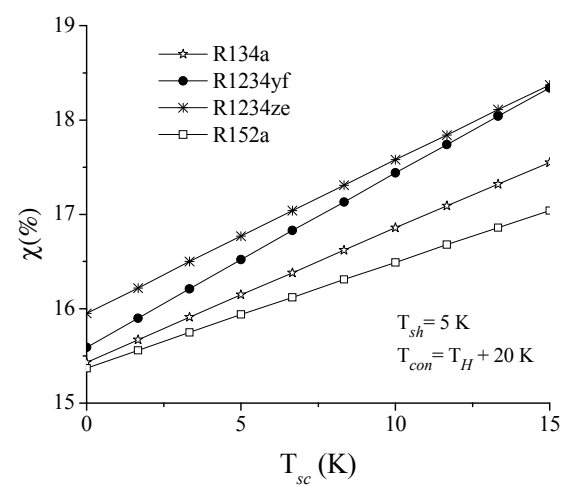

(b)

Figure 5. Effect of sub-cooling degree on second law efficiency when the entropy production in the IHX is maximum: (a) superheating equal to zero, (b) superheating equal to $5 \mathrm{~K}$. 
In addition, the refrigerant R1234ze shows a second law efficiency higher than the R134a up to $3.5 \%$ for the same sub-cooling degree. From the graph, it can be seen that for sub-cooling values below $4.5 \mathrm{~K}$, the refrigerant R152a is better than the other refrigerants proposed, including R134a. When considering $5 \mathrm{~K}$ of superheating degree as shown in Figure 5b, it can be seen that R152a is the less affected with only $9.4 \%$ of second law efficiency increase. The R1234yf turned out to be the best in the system with a second law efficiency increase of $15.4 \%$. Accordingly, it can be concluded that sub-cooling must be considered an important variable in order to increase the second law efficiency, mainly helping the R1234yf refrigerant.

\subsection{Evaporating and Condensing Temperature Influence}

The effect of the evaporating temperature on the second law efficiency is shown in Figure 6. No sub-cooling or superheating degree is considered. It can be observed that the maximum efficiency is reached when using R152a, while the minimum value is showed by the R1234yf. The difference in energy efficiency ratio between R152a and R1234ze is only 1\%, while when comparing R152a with $\mathrm{R} 1234 \mathrm{yf}$, the difference on second law efficiency is $11 \%$. When the evaporating temperature increases, the cooling capacity increases and reduces compression work. This means that the efficiency by the Second Law increases.

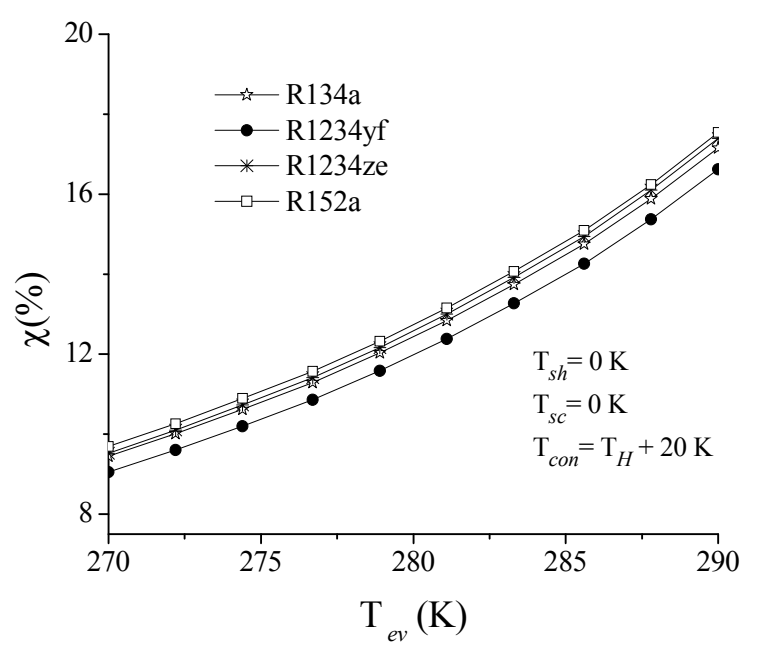

Figure 6. The behavior of efficiency by Second Law as a function of the evaporation temperature.

Figure 7 shows the reduction in second law efficiency by effect of increases the condensation temperature for all refrigerants. In this figure, the values of sub-cooling and superheating degrees are considered zero. The refrigerant with the lowest second law efficiency is R1234yf. It is $12.5 \%$ lower than the second law efficiency showed by the R152a which is the one with the highest second law efficiency at a condensing temperature of $350 \mathrm{~K}$. Secondly, at the same condensing temperature, the refrigerant with the major second law efficiency is the R1234ze, which is only 1\% above R134a. With increasing condensing temperature, the cooling capacity decreases, and therefore the mass flow rate of refrigerant increases, in this way, efficiency by the Second Law decreases. 


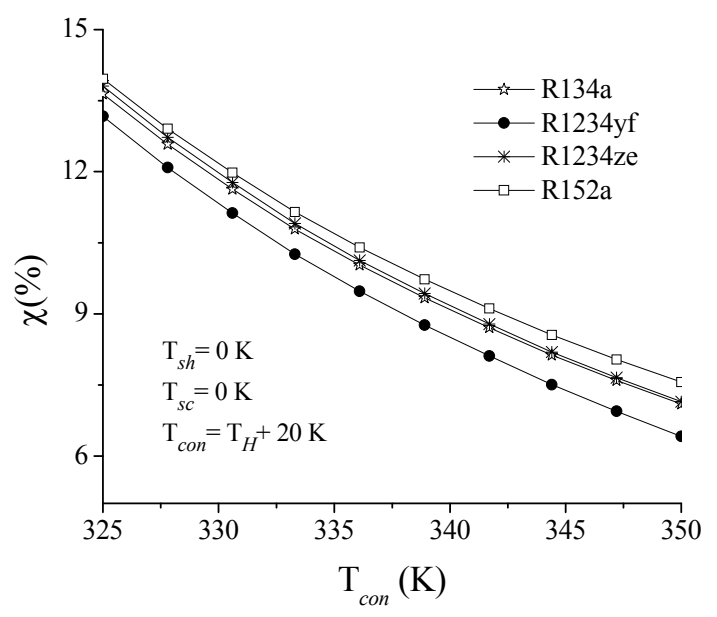

Figure 7. Behavior of the efficiency of the Second Law depending on the condensation temperature.

\subsection{Isentropic Efficiency and Effectiveness IHX Influence}

Figure 8 shows the results of relative exergy destruction in relation to isentropic efficiency for each refrigerant including R134a for maximum entropy generation into IHX (Figure 3). According to these results, it can be seen the influence of isentropic efficiency on exergy destruction ratio, being the compressor and condenser the components with more exergy destruction ratio followed by the evaporator, the expansion valve and IHX for all refrigerants analyzed. Here, the range of isentropic efficiency with most irreversibilities in the compressor is approximately $10-62 \%$, while for a range of around to $62-100 \%$ is the condenser, the component with most exergy destruction.

Also, from the graphs it is showed that the evaporator overcomes the compressor exergy destruction for an isentropic efficiency of $80 \%$ approximately and, the expansion valve for an isentropic efficiency of $90 \%$.

Accordingly, it can be noticed that the refrigerant that showed the higher value in relative exergy destruction in the compressor is R1234yf overcoming the system by $8 \%$ with R134a when an IHX is used. Furthermore, it is the refrigerant with fewer irreversibilities in the condenser and evaporator with $10 \%$ and $6.5 \%$ less respectively, when compared with the baseline refrigerant.

On the other hand, R1234ze could be a good option for drop-in replacement of R134a because after R152a is the refrigerant with less exergy destruction in comparison with the R1234yf and R134a. Kabeel et al. [26], showed R1234ze can be used in applications for evaporating temperatures above $260.15 \mathrm{~K}$ and also, power consumption is lower than R134a by about $9 \%$ to $15 \%$.

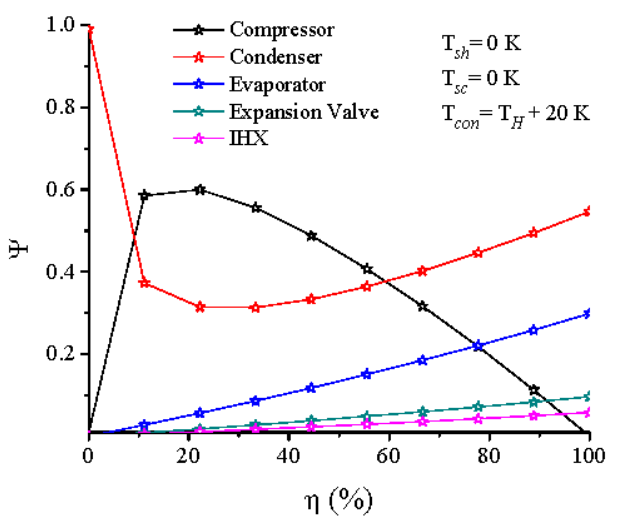

(a)

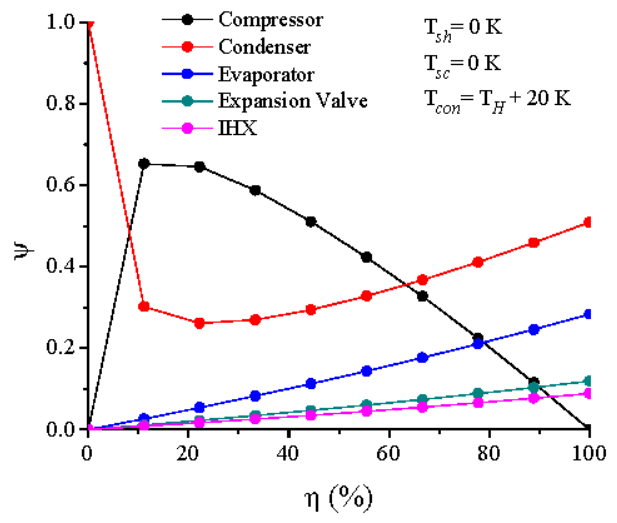

(b)

Figure 8. Cont. 


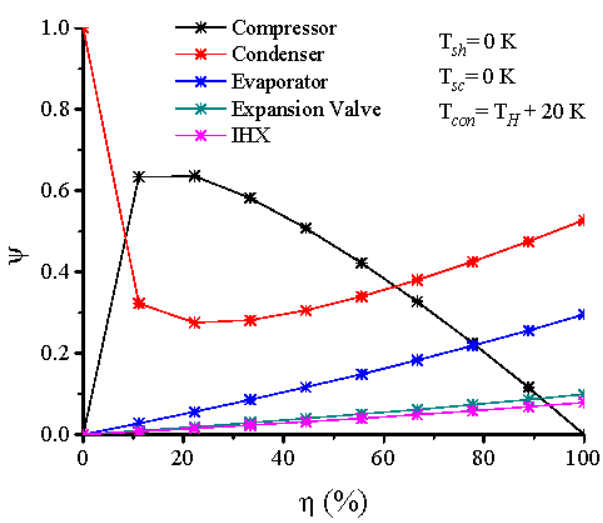

(c)

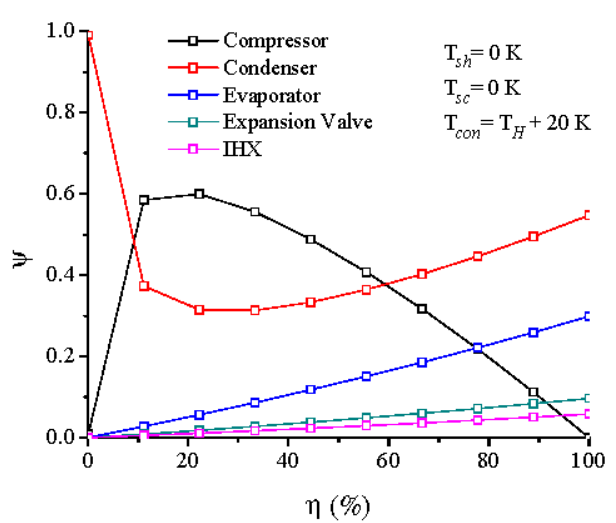

(d)

Figure 8. Relative exergy destruction in the system when the entropy production in the IHX is maximum: (a) R134a, (b) R1234yf, (c) R1234ze, (d) R152a.

Finally, Figure 9 presents the results obtained in the system using an exergy analysis considering a zero sub-cooling degree and zero superheating degree. Also, the results show that the refrigerant with the greatest exergy efficiency is R152a, overcoming R1234yf by $16 \%$, while the difference between R152a and R134a is 8\%. Also, the difference between the R134a and R1234ze refrigerants is the lowest, which is $3 \%$.

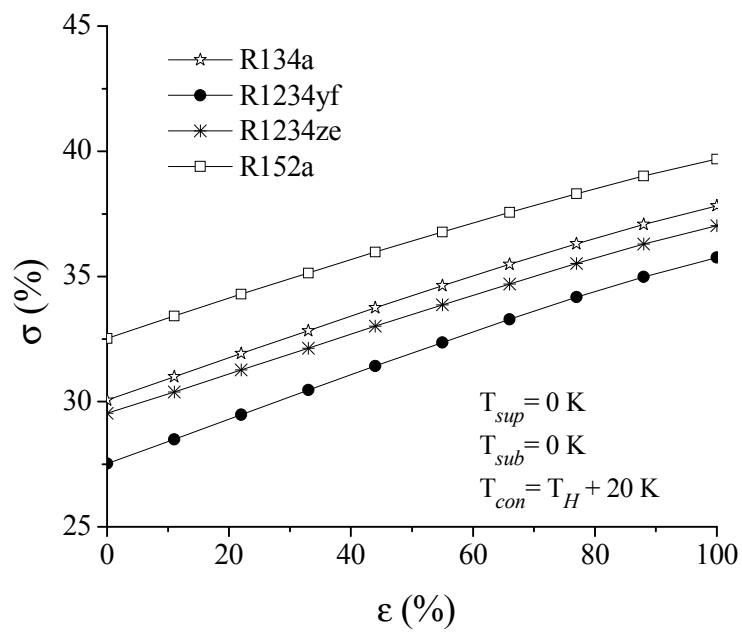

Figure 9. Behavior of the exergetic efficiency system vs. the effectiveness of the IHX.

According to this Figure, although R152a could be the best refrigerant, this is not an option recommended as a drop-in replacement of R134a in cycle with IHX because in mobile air conditioning applications, compressor discharge temperature is high and the condition causes high insecurity in the system due to the flammability of the refrigerant.

\section{Conclusions}

In this paper, a Second Law Analysis of a mobile air conditioning system using internal heat exchanger (IHX) with alternative refrigerants to R134a has been presented. The conclusions of the present analysis are summarized below:

1. Considering the point at which the maximum entropy production is reached in the IHX, the use of R1234yf is recommended for a super-heating degree above $8.5 \mathrm{~K}$, since it is at this point 
where second law efficiency reaches its highest possible value, the above, when no sub-cooling is present.

2. The mobile air conditioning system using R1234ze is found to be most efficient than the other refrigerants, because its performance is similar to R134a, even with the integration of the IHX. In fact, it is more efficient than the R152 when the effectiveness is up to $70 \%$.

3. The sub-cooling and superheating effect is a considerable variable in the efficiency by Second Law because, with this parameter, the second law efficiency of the system increases, improving mainly R1234yf.

4. Although R152a shows better exergy performance, this refrigerant is not recommended as a drop-in replacement due to its high flammability. The use of this refrigerant is only recommended when used in a secondary loop.

5. Influence of isentropic efficiency on the system exhibits the maximum exergy destruction on the compressor and in the condenser for all refrigerant options, including R134a.

6. By the use of IHX in the system, second law efficiency increased for all refrigerants. The best performance is found using R152a and worst performance is observed using R1234yf.

Acknowledgments: The authors wish to thank the University of Guanajuato by the support in the realization of this article.

Author Contributions: Vicente Pérez-García conceived and made some simulations of the thermodynamic model, Juan M. Belman-Flores complemented simulations; José L. Rodríguez-Muñoz supported in the elaboration of graphics and development of model; Vicente Pérez-García, Victor H. Rangel-Hernández and Armando Gallegos-Muñoz wrote the paper. All authors have read and approved the final manuscript.

Conflicts of Interest: The founding sponsors had no role in the design of the study; in the collection, analyses, or interpretation of data; in the writing of the manuscript, and in the decision to publish the results.

\section{Subscripts}

$\begin{array}{ll}\text { COP } & \text { Coefficient of performance } \\ e & \text { Specific exergy }(\mathrm{kJ} / \mathrm{kg}) \\ h & \text { Specific enthalpy }(\mathrm{kJ} / \mathrm{kg}) \\ q & \text { Specific heat }(\mathrm{kJ} / \mathrm{kg}) \\ s & \text { Specific entropy }(\mathrm{kJ} / \mathrm{kg} \mathrm{K}) \\ T & \text { Temperature }(\mathrm{K}) \\ W & \text { Specific compressor work }(\mathrm{kJ} / \mathrm{kg})\end{array}$

\section{Subscripts}

C

Compressor

$1,2,3, \ldots 6$

0

Thermodynamic states

$\mathrm{H}$

Reference state

H Outdoor

L Indoor

sc Sub-cooling

sh Superheating

exp Expansion device

con Condenser

ev Evaporator

IHX Internal heat exchanger

$\mathrm{R} \quad$ Reversible process

sys System

sup Supplied

rec Recovery

eq Equipment 


\section{Greek Symbols}

$\begin{array}{ll}\varepsilon & \text { IHX effectiveness } \\ \eta & \text { Isentropic efficiency } \\ \Delta & \text { Losses (kJ/kg K) } \\ \chi & \text { Second Law Efficiency } \\ \delta & \text { Specific entropy generated }(\mathrm{kJ} / \mathrm{kg} \mathrm{K}) \\ \Psi & \text { Relative exergy destruction } \\ \sigma & \text { Exergetic efficiency system }\end{array}$

\section{References}

1. UNEP. HFCs: A Critical Link in Protecting Climate and the Ozone Layer-A Synthesis Report; UNEP: Nairobi, Kenya, 2011.

2. Regulation, EU No 517/2014 of the European Parliament and the Council of 16 April 2014 on Fluorinated Greenhouse Gases and Repealing Regulation (EC) No 842/2006. Available online: http:/ /www.eea.europa. eu/policy-documents/regulation-eu-no-517-2014 (accessed on 18 April 2017).

3. Brown, J.S. Introduction to hydrofluoro-olefin alternatives for high global warming potential hydrofluorocarbon refrigerants. HVACER Res. 2013, 19, 693-704.

4. Kedzierski, M.A.; Brown, J.S.; Koo, J. Performance ranking of refrigerants with low global warming potential. Sci. Technol. Built Environ. 2015, 21, 207-219. [CrossRef]

5. Bryson, M.; Dixon, C.; StHill, S. Testing of HFO-1234yf and R152a as mobile air conditioning refrigerant replacements. Ecolibrium 2011, 2011, 30-38.

6. Molés, F.; Navarro-Esbrí, J.; Peris, B.; Mota-Babiloni, A.; Barragán-Cervera, A. Theoretical energy performance evaluation of different single stage vapour compression refrigeration configurations using R1234yf and R1234ze(E) as working fluids. Int. J. Refrig. 2014, 44, 141-150. [CrossRef]

7. Jignesh, G.; Rangesh, K. Thermodynamic cycle analysis of mobile air conditioning system using HFO-1234yf as an alternative replacement of HFC-134a. Int. J. Sci. Eng. Technol. Res. 2016, 5, 234-247.

8. Lee, Y.; Jung, D. A brief performance comparison of R1234yf and R134a in a bench tester for automobile applications. Appl. Therm. Eng. 2012, 35, 240-242. [CrossRef]

9. Zhao, Y.; Chen, J.; Xu, B.; He, B. Performance of R-1234yf in mobile air conditioning system under different heat load conditions. Int. J. Air Cond. Ref. 2012, 20, 1250016. [CrossRef]

10. Zhao, Q. Performance improvements potentials of R1234yf mobile air conditioning system. Int. J. Refrig. 2015, 58, 35-40.

11. Zilio, C.; Brown, J.S.; Schiochet, G.; Cavallini, A. The refrigerant R1234yf in air conditioning systems. Energy 2011, 36, 6110-6120. [CrossRef]

12. Navarro-Esbrí, J.; Mendoza-Miranda, J.M.; Mota-Babiloni, A.; Barragán-Cervera, A.; Belman-Flores, J.M. Experimental analysis of R1234yf as a drop-in replacement for R134a in a vapor compression system. Int. J. Refrig. 2013, 36, 870-880. [CrossRef]

13. Gomaa, A. Performance Characteristics of Automotive Air Conditioning System with Refrigerant R134a and its Alternatives. Int. J. Energy Power Eng. 2015, 50, 168-177. [CrossRef]

14. Yataganbaba, A.; Kilicarslan, A.; Kurtbas, I. Exergy analysis of R1234yf and R1234ze as R134a replacement in a two evaporator vapour compression refrigeration system. Int. J. Refrig. 2015, 60, 26-37. [CrossRef]

15. Özgür, A.E.; Kabul, A.; Önder, K. Exergy analysis of refrigeration systems using an alternative refrigerant (hfo1234yf) to R-134a. Int. J. Low Carbon Technol. Adv. Access 2012, 9, 1-7.

16. Cho, H.; Park, C. Experimental investigation of performance and exergy analysis of automotive air conditioning systems using refrigerant R1234yf at various compressor speeds. App. Therm. Eng. 2016, 101, 30-37. [CrossRef]

17. Pottker, G.; Hrnjak, P. Experimental investigation of the effect of condenser subcooling in R134a and R1234yf air-conditioning systems with and without internal heat exchanger. Int. J. Refrig. 2015, 50, 104-113. [CrossRef]

18. Golzari, S.; Kasaeian, A.; Daviran, S.; Mahian, O.; Wongwises, S.; Sahin, A.Z. Second Law analysis of an automotive air conditioning system using HFO-1234yf, an environmentally friendly refrigerant. Int. J. Refrig. 2017, 73, 134-143. [CrossRef] 
19. Bilen, K.; Kalkisim, A.T.; Solmus, I. The performance of an alternative refrigerant gas R152a as mobile air conditioning refrigerant. Chem. Eng. Trans. 2014, 39, 1801-1806.

20. Jignesh, K.V.; Ragesh, G.K. A brief literature survey on an Automobile Air-Conditioning System. Int. J. Eng. Dev. Res. 2014, 2, 558-570.

21. Subiantoro, A.; Ooi, T.K.; Stimming, U. Energy Saving Measures for Automotive Air Conditioning (AC) System in the Tropics. In Proceedings of the 15th International Refrigeration and Air Conditioning Conference at Purdue, West Lafayette, IN, USA, 14-17 July 2014.

22. Herold, K.E. Performance limits for the thermodynamics cycles. Adv. Heat Pumps 1989, 7, 15-22.

23. Krakow, K.I. Relationships between Irreversibility, Exergy Destruction, and Entropy Generation for Systems and Components. Available online: http://www.techstreet.com/standards/3735-relationships-betweenirreversibility-exergy-destruction-and-entropy-generation-for-systems-and-components?product_id= 1716402 (accessed on 18 April 2017).

24. Fartaj, A.; Ting, D.S.K.; Yang, W.W. Second Law analysis of the transcritical $\mathrm{CO}_{2}$ refrigeration cycle. Energy Convers. Manag. 2004, 45, 2269-2281. [CrossRef]

25. Dincer, I.; Rosen, M.A. Exergy: Energy, Environment and Sustainable Development; Elsevier: Amsterdam, The Netherlands, 2007.

26. Kabeel, A.E.; Khalil, A.; Bassuoni, M.M.; Raslan, M.S. Comparative experimental study of low GWP alternative for R134a in a walk-in cold room. Int. J. Refrig. 2016, 69, 303-312. [CrossRef]

(C) 2017 by the authors. Licensee MDPI, Basel, Switzerland. This article is an open access article distributed under the terms and conditions of the Creative Commons Attribution (CC BY) license (http:/ / creativecommons.org/licenses/by/4.0/). 